\title{
Solar energy and the circular economy: An introduction
}

MRS Energy \& Sustainability links materials research with technological forecast, policy, and social change. Inspired by a large European initiative on carbon dioxide $\left(\mathrm{CO}_{2}\right)$ reduction and synthetic fuel production powered by solar energy (SUNRISE [1]), we invited papers for a special issue on circular economy. By circular economy, we simply understand the return of used material back into production, also known as "recycling". The hierarchy of waste and waste management (compare [2]) has led to the 3R (Reduce, Reuse, and Recycle) and eventually 4R principle (Recover), which includes resource management.

In the worst case, spent material ends up in the pure environment as illegally deposited waste. Legal ways of waste disposal include adding to landfills or burning in incinerators, the latter of which will bring about heat, which can be used for district heating, and ash, which may contain valuable materials including noble metals. More sophisticated ways of waste disposal encompasses recycling methods, which, depending on the material and industry, can represent an industry of its own.

The ancient Greeks and Romans collected metal and glass, and remelted them, showing that recycling is nothing new. Likewise, circular economy is not new, as Sikdar points out [3]. The SUNRISE initiative aims to expand the technology of the circular economy toward $\mathrm{CO}_{2}$ assimilation. This is the type of circular economy which has been demonstrated in the natural world for billions of years. This is known as carbon cycle [4] and includes one of the most fundamental processes of primary production by photosynthesis. Practically, this is the conversion of atmospheric $\mathrm{CO} 2$ (and $\mathrm{CO} 2$ from industrial point sources) along with water to hydrocarbon fuels (which Melvin Calvin projected as petroleum plantations [5]) and base chemicals. It also includes the production of nitrogen compounds such as ammonia [6,7], which has its own biogeochemical cycle. The necessary energy for powering these cycles shall come from renewable sources, primarily from solar energy. Worldwide research activity on renewable energy can easily be interpreted as circular economy research efforts.

The contributions to this special issue serve as a snapshot of technical efforts and policy worldwide toward use of renewable energy, some of it well established and some quite novel. We hope that readers will find inspiration to further their own work or encourage the work of others to further these goals toward a circular economy fueled by solar energy.

Fermeglia et al. warn of a "storm" of food and water shortage, increased energy prices, and detrimental effects on the environment [8], to be expected in the not too distant future unless mankind turns to renewable energy technology, which was inspired over 100 years ago by Ciamician [9]. The paper by Erat showcases one such example in the Turkish national program for the energy transition from fossil to renewable [10].

Decentralization of production facilities is part of the SUNRISE concept and addressed in the paper by Krasnoholovets [11]. Lorge points out that the world economy is predominantly a thermal economy, which should be replaced by an electroprotonic economy (call it hydrogen economy) as soon as possible [12]. Aguey-Zinsou et al. clarify in their review on renewable hydrogen for the chemical industry [13] as how hydrogen, the prospective fuel of the future, has for a long time been used already in many industries. Hence, hydrogen is nothing new for many established industries.

Successful capturing of $\mathrm{CO}_{2}$ from the air, other than by production of biomass by agriculture and forestry and ocean plankton, can help meet the goals of the Paris Agreement. Pettinari and Tombesi present two papers on the use of molecular frameworks for carbon dioxide storage [14] and carbon dioxide conversion [15]. Hernandez and Sheehan [16] present a carbon dioxide reduction technology, which can outperform the natural $\mathrm{CO}_{2}$ assimilation of trees. The molecular mechanisms of photosynthesis, and artificial photosynthesis, as projected by Ciamician, are very difficult to expose. The principles of electrochemical conversion of hydrogen, $\mathrm{CO}_{2}$, and nitrogen toward fuels and chemicals and their subsequent decomposition can be easily sketched in chemical reaction equations. But the exploration of the mechanistic details of the reactions taking place in reactor materials is not trivial and requires sophisticated analytical methods. Naldoni et al. provide a review of the novel operando and in situ analytical methods for the study of photoelectrochemical systems in this respect [17].

Plastic, a valuable industrial solid lightweight hydrocarbon with countless applications and a genuine material of the twentieth century, has come under scrutiny as not being environmentally benign. While its degradation produces mostly water and carbon dioxide-principal ingredients for the global biogeochemical cycle, degradation times can be very long in the environment. Bora reviews the biotechnological degradation of waste plastics [18].

Guest Editors: Artur Braun, Rita Toth, and Selma Erat 


\section{REFERENCES}

1. A. Abbott, Europe's next euro1-billion science projects: six teams make it to final round. Nature 566, 164-165 (2019)

2. K. Wolf, Source reduction and the waste management hierarchy. JAPCA 38, 681-686 (1988)

3. S. Sikdar, Circular economy: is there anything new in this concept? Clean Technol. Environ. Policy 21, 1173-1175 (2019)

4. M. Calvin, Nobel Lecture - The Path of Carbon in Photosynthesis (Elsevier Publishing Company, Amsterdam, 1961).

5. M. Calvin, Petroleum Plantations, Solar Energy, Nagoya, Japan, 1979, pp. 1-30.

6. J. Witte, Power to Ammonia - Feasibility Study for the Value Chains and Business Cases to Produce $\mathrm{CO}_{2}$-Free Ammonia Suitable for Various Market Applications-Free Ammonia Suitable for Various Market Applications (Institute for Sustainable Process Technology, Amersfoort, The Netherlands, 2017).

7. O. Elishav, D.R. Lewin, G.E. Shter, G.S. Grader, The nitrogen economy: economic feasibility analysis of nitrogen-based fuels as energy carriers. Appl. Energy 185, 183-188 (2017)

8. M. Fermeglia, V. Lughi, A. Massi Pavan, How to avoid the perfect storm: the role of energy and photovoltaics. MRS Energy Sustain. (2020). https://doi.org/10.1557/mre.2020.36

9. G. Ciamician, The photochemistry of the future. Science 36, 385394 (1912)

10. S. Erat, Turkey's energy transition from fossil based to renewable up to 2030: milestones, challenges and opportunities. Clean Technol. Environ. Policy (2020). https://doi.org/10.1007/s10098-02001949-1
11. V. Krasnoholovets, V. Zabairachnyi, Technologies to assist in the energy transition to the next century. MRS Energy Sustain. (2020). https://doi.org/10.1557/mre.2020.23

12. P. Lorge, Sustainable integration of human activities into the global ecosystem. MRS Energy Sustain. 7, 29 (2020)

13. N. Rambhujun, M.S. Salman, T. Wang, C. Pratthana, P. Sapkota, M. Costalin, Q. Lai, K.-F. Aguey-Zinsou, Renewable hydrogen for the chemical industry. MRS Energy Sustain. (2020). https://doi. org/10.1557/mre.2020.33

14. C. Pettinari, A. Tombesi, Metal-organic frameworks for carbon dioxide capture. MRS Energy Sustain. (2020). https://doi. org/10.1557/mre.2020.30

15. C. Pettinari, A. Tombesi, Metal-organic frameworks for chemical conversion of carbon dioxide. MRS Energy Sustain. (2020). https ://doi.org/10.1557/mre.2020.35

16. S. Gonzalez Hernandez, S.W. Sheehan, Comparison of carbon sequestration efficacy between artificial photosynthetic carbon dioxide conversion and timberland reforestation. MRS Energy Sustain (2020). https://doi.org/10.1557/mre.2020.32

17. R. Yalavarthi, O. Henrotte, A. Minguzzi, P. Ghigna, D.A. Grave, A. Naldoni, Operando characterizations of photoelectrochemical cells for solar fuels and chemicals. MRS Energy Sustain. (2020). https://doi.org/10.1557/mre.2020.37

18. D.K. Bora, Rise of the sustainable circular economy platform from waste plastics: a biotechnological perspective. MRS Energy Sustain. (2020). https://doi.org/10.1557/mre.2020.28 